\title{
TOTEM E TABU: VIDA COTIDIANA
}

Bruno Wagner D'Almeida de Sousa Santana'

\section{Resumo}

No presente artigo o autor procura fazer um breve estudo do texto Totem e tabu: algumas concordâncias entre a vida anímica dos selvagens e a dos neuróticos, escrito por Freud em 1913. Destacando os principais pontos discutidos por Freud em cada capítulo da obra, o principal intento do autor é mostrar que ao contrário da interpretação que se costuma fazer, Freud não escreve esse texto para distanciar "primitivo" e "civilização", como se fossem etapas maturacionais do processo do desenvolvimento humano, linearmente em ascensão evolutiva. A temporalidade que orienta Freud em Totem e tabu não busca distanciar "primitivo" e "civilizado", busca antes aproximá-los, busca mostrar o que há neles de concordância, como fica explícito no próprio subtítulo da obra: algumas concordâncias entre a vida anímica dos selvagens e a dos neuróticos.

PALAVRAS-CHAVE: Psicanálise. Totem. Temporalidade. Índios. Civilização.

\footnotetext{
1 Psicanalista e filósofo. Doutor em Filosofia pela PUC-RJ. Mestre em Filosofia também pela PUC-RJ. Graduado em Psicologia pela Universidade Federal de Juiz de Fora (UFJF) e em Filosofia pelo Centro de Ensino Superior de Juiz de Fora (CES-JF). Praça Almirante Jaceguai, 72, apto.602, 20240-000, Bairro de Fátima, Rio de Janeiro, RJ. 21-999919051. brunowagnersou@yahoo.com.br
} 


\section{TOTEM E TABU: VIDA COTIDIANA}

Venho ouvindo da parte de pessoas que se colocam como psicanalistas formulações que dizem que os índios não têm simbólico, que "não são nem capazes de amar", que eles vivem se devorando uns aos outros enquanto "nós fazemos nossas comunhões com doces", que a ascensão do simbólico se deu através da cruz cristã, que a cultura indígena "é uma cultura que não se desenvolve porque eles matam os chefes deles a facadas", e por aí vai. Não estaria falando disso aqui se não fosse pela proximidade de onde venho ouvindo essas atrocidades, me assusta muito ouvir coisas assim e vindo de onde vêm. Por conta disso - como se já não bastasse a enorme influência que o texto de Lévi-Strauss, intitulado A eficácia simbólica, teve sobre Lacan - mas também pela relevância do próprio texto, resolvi tentar fazer uma breve apresentação da maneira como interpreto a obra Totem e Tabu: algumas concordâncias na vida anímica dos selvagens e dos neuróticos (1913), de Freud, a fim de mostrar que Freud não se interessou pelo tema do totemismo para traçar o que seria uma antipsicanalítica e equivocada teoria da evolução mental, equívoco no qual, segundo Lacan, os analistas parecem por vezes recair (LACAN, 1986, p.131), mas por conta da semelhança que encontrou entre a maneira de operar do pensamento neurótico e a do pensamento dos "chamados" (FREUD, 2014, p.11) primitivos.

Como próprio subtítulo do texto de Freud diz - "algumas concordâncias na vida anímica dos selvagens e dos neuróticos" - , mais do que distanciar e distinguir, o que Freud faz nessa obra consiste, sobretudo, em aproximar o funcionamento do neurótico e o funcionamento do primitivo, em se debruçar sobre o funcionamento primitivo do neurótico. E o viés para essa aproximação é o viés pulsional. Freud não está ocupado com o mérito intelectual (FREUD, 2014, p.96) da questão; como em todas as suas obras, não está ocupado com o que seria uma apreensão intelectualmente correta e adequada da realidade, até porque o que as neuroses apresentam é que nenhuma apreensão da realidade consegue elidir a dimensão conflituosa e ambivalente dos fluxos pulsionais, dimensão essa que o sintoma, em sua natureza bi-escindida (FREUD, 2014, p.68), busca recobrir, na medida em que surge como formação que salta e se produz entre duas intensidades contrapostas, por exemplo, de sentimentos ternos, por um lado, e hostis, por outro - buscando então conciliar essas duas intensidades, malgrado essa conciliação, no entanto, nunca se efetive por completo, de modo que a almejada integridade do eu e do 
indivíduo dá sempre lugar à uma ineliminável divisão do sujeito, no que este se encontra permanentemente dividido entre intensidades contrapostas, entre direções pulsionais divergentes e contrapostas.

Totem e tabu está dividido em quatro partes: a primeira trata do horror ao incesto; a segunda trata do tabu e da ambivalência de sentimentos; a terceira trata do animismo e da onipotência dos pensamentos; e a quarta trata do retorno do totemismo na infância. Em todas essas quatro partes, nos seus quatro eixos de investigação o incesto, o tabu, o totemismo e a criança - Freud faz uma aproximação, traça concordâncias entre o neurótico e os chamados primitivos. Já era de se esperar o desconforto que isso geraria em meio àqueles que se sentem ocupando o cume do desenvolvimento humano, o suposto máximo grau da evolução da consciência jamais alcançado em todos os tempos. No entanto, como se já não bastasse o que ouvia na sua clínica, Freud viveu no período em que as populações que se consideravam as mais evoluídas e civilizadas se viram em meio à uma barbárie de proporções nunca antes vista, Freud viveu o período das duas maiores guerras mundiais, guerras que contaram com um número de mortos jamais visto antes; as ditas culturas simbolicamente mais evoluídas mostravam assim a sua outra face, a produção de morte em massa, aonde populações inteiras se viram dizimadas em nome de um Império.

O que Freud retira daí? Que nenhuma moral foi capaz de eliminar as moções hostis; lidar com o conflito é algo que não se consegue erradicar, assim como para Lacan o Real é algo que o Simbólico não consegue recobrir por inteiro (LACAN, 2008, p.40).

Sabendo das críticas que iria receber por conta de fazer uma aproximação entre o modo de operar dos neuróticos e o modo de operar dos povos "chamados" primitivos (sobre os quais vemos ainda hoje um genocídio em curso), Freud escreve:

\begin{abstract}
Não nos escapa que com esses intentos de explicação nos expomos a um reproche: atribuiríamos aos selvagens contemporâneos uma fineza de atividades anímicas que excede o verossímil. Mas, opino, facilmente poderia suceder-nos com a psicologia desses povos que permaneceram no estádio animista o que ocorre com a vida anímica da criança: nós, os adultos, já não a compreendemos, e isso se deve a que tenhamos subestimado tanto a sua riqueza e sutileza. (FREUD, 2014, p.103)
\end{abstract}

Uma boa definição para um hospital-maternidade seria: casa onde se encontram seres primitivos? Na inquisição se dizia que o índio não tinha "alma", em extensão a isso, hoje há quem diga que o índio não tem "simbólico". Mas nem Lacan 
nem Freud vão por aí: dizer que o índio não tem "simbólico", essa é já uma interpretação selvagem da psicanálise. Muito pelo contrário, o que Lacan toma das culturas indígenas para o seu ensino é justamente, por meio da antropologia de LéviStrauss, a operação da "eficácia simbólica", que por sua vez o motivará (LACAN, 2005, p.89) a elaborar a teoria dos três registros (o Real, o Simbólico e o Imaginário).

A primeira parte do livro, onde trata do horror ao incesto, é a parte onde Freud usa os piores termos para se referir aos "primitivos", o que soa às vezes um tanto irônico tendo em vista que Freud não cessa de apontar as características atribuídas aos ditos primitivos como estando presentes também nos ditos civilizados. Há que se levar em conta aí também que Freud está se utilizando de anotações de antropólogos que, como o próprio Freud afirma, não escapam à crítica de estarem centrados nos seus próprios pontos de vista (FREUD, 2014, p.111) (o que em antropologia é chamado de "etnocentrismo"), que vêem a partir de suas próprias lentes, que não dominam a língua dos povos observados e que muitas vezes descrevem acontecimentos que foram compilados por terceiros, e não por eles próprios, sendo assim difícil comprovar algo nesse campo (FREUD, 2014, p.105).

A fim de verificar se a sua premissa é correta, isto é, a de que os povos chamados selvagens são "em certo sentido nossos contemporâneos" (FREUD, 2014, p.11), Freud escolhe as tribos que os etnógrafos (sobretudo Frazer) descreveram como sendo as mais atrasadas, que no caso seriam os primeiros povos da Austrália (FREUD, 2014, p.11). Todavia, o que Freud vai mostrar é que "estes selvagens que, segundo nossos padrões, careceriam de toda norma ética" (FREUD, 2014, p.14), "se impuseram um alto grau de restrição às suas pulsões sexuais, [e] não obstante, nos inteiramos de que fixaram como meta, com o maior cuidado e a severidade a mais penosa, evitar relações sexuais incestuosas" (FREUD, 2014, p.12); a organização social dessas populações estão centradas e divididas a partir da evitação do incesto. Segundo Freud, a proibição do incesto faz a eleição do objeto de amor deslizar da imagem da mãe, ou até mesmo da irmã, até parar em pessoas alheias que encarnam a imagem especular daquelas (FREUD, 2014, p.25). O horror ao incesto figura aí para Freud como um traço infantil e como uma concordância com a vida psíquica do neurótico (FREUD, 2014, p.26), e assim como nos "selvagens" a organização familiar se divide em duas metades matrilineares, cada uma com dois clãs totêmicos, organizadas dessa maneira para evitar as relações incestuosas (FREUD, 2014, p.17), também nos povos "civilizados" a organização familiar está centrada na evitação do 
incesto, estendendo a proibição da relação sexual entre pais e filhos à relação sexual entre primos, entre padrinhos e afilhados (FREUD, 2014, p.19), entre o genro e a sobrinha (FREUD, 2014, p.23), entre o genro e sogra, a nora e sogro, por exemplo.

Na segunda parte, Freud examina o tabu, palavra polinésia de difícil tradução e que possui significados contrapostos: "sagrado" assim como "proibido" (FREUD, 2014, p.27). Freud diz que aparentemente esse seria um problema longínquo de nós, aparentemente seria uma característica específica das culturas primitivas, movidas pela crença em espíritos (FREUD, 2014, p.31). Todavia, vai ele adiante e considera esse um problema psicológico que merece uma tentativa de solução: "Aguçaremos então os ouvidos" (FREUD, 2014, p.31), diz ele,

Vislumbramos que o tabu dos selvagens da Polinésia poderia não ser algo tão remoto para nós como suporíamos à primeira vista, que as proibições a que nós mesmos obedecemos, instituídas pela moral e os costumes, possivelmente têm um parentesco essencial com este tabu primitivo, e que se esclarecermos o tabu talvez lancemos luz sobre a obscura origem do nosso próprio "imperativo categórico" (FREUD, 2014, p.31).²

A primeira concordância que Freud vê entre as proibições obsessivas nos neuróticos e o tabu é que elas não se ligam à ameaças externas, mas à uma consciência moral aparentemente imotivada que, no entanto, gera ao mesmo tempo uma angústia irrefreável. Nesse sentido, o máximo que os obsessivos às vezes conseguem dizer é que alguém do seu entorno sofreria algum dano caso ele próprio violasse a proibição que o obceca. A segunda concordância é que a proibição nuclear da neurose, assim como no tabu, diz respeito ao "contato", à angústia do contato (seja corporalmente ou pelo pensamento), diz respeito ao "delírio de tocar". A terceira concordância diz respeito ao "deslocamento" das proibições; elas se propagam de um objeto [substitutivo] a outro a partir de conexões quaisquer (FREUD, 2014, p.35); e como no tabu, no obsessivo a violação pode ser compensada por um cerimonial compulsivo (FREUD, 2014, p.36).

Segundo Freud, o tabu talvez seja a forma mais antiga da consciência moral, e a sua violação gera um grande sentimento de culpa, ainda que essa violação tenha se dado sem que o sujeito quisesse violar algo conscientemente, como no caso da tragédia de Édipo (FREUD, 2014, p.73), em quem o fato de ter ultrapassado a lei da pólis sem saber que o estava fazendo não anula seu sentimento de culpa. O tabu e a consciência moral não são portanto supérfluos, mas justificáveis por conta da

\footnotetext{
${ }^{2}$ Embora Freud não o diga, faz aí alusão à expressão referente à consciência moral em Kant.
}

Psicanálise \& Barroco em revista | v.16, n. 01 | julho de 2018 
ambivalência de sentimentos (FREUD, 2014, p.75) que cada homem porta consigo. $\mathrm{Na}$ base da proibição figurada pelo tabu age uma corrente positiva (FREUD, 2014, p.74), de valor positivo, isto é, de intensidade mais, corrente positiva que por sua vez é inconsciente (FREUD, 2014, p.75) e desde aí exerce pressão no aparelho psíquico. A conciência moral é "um sintoma reativo frente à tentação ocultada no inconsciente" (FREUD, 2014, p.74): "a proibição é expressa e consciente; por outro lado, o prazer do contato, que perdura, é inconsciente: a pessoa nada sabe dele" (FREUD, 2014, p.37), embora a atividade pulsional em busca do prazer esteja agindo constantemente, se deslocando continuamente a fim de escapar dos obstáculos interpostos pela consciência (FREUD, 2014, p.38). O fundamento do tabu, na sua dimensão proibitiva, se encontra paradoxalmente assim na inclinação contrária manifesta pelo inconsciente, na sua "intensa inclinação" para agir contra a proibição (FREUD, 2014, p.40), para além da lei. Tudo aquilo que assim viola o tabu e atiça a ambivalência se torna um novo tabu, pois na medida em que acena para um gozo (FREUD, 2014, p.40) além da proibição da lei, ameaça com o que seria a dissolvição da sociedade (FREUD, 2014, p.41) - caso por contágio todas as pessoas do grupo resolvessem ir na mesma direção que o transgressor. Segundo Freud, na base da obediência ao tabu há, portanto, uma renúncia (FREUD, 2014, p.42), o que no entanto não elimina a ambivalência de sentimentos. $E$ o alto grau que essa ambivalência de sentimentos pode atingir forma, por sua vez, a predisposição à neurose (FREUD, 2014, p.66). A diferença aqui com relação ao tabu é que, para Freud, o tabu não é uma neurose, mas uma formação social, uma criação cultural (FREUD, 2014, p.76), e não se restringe a um processo particular e subjetivo.

$\mathrm{Na}$ terceira parte Freud se dedica "à concepção em extremo assombrosa que sobre a natureza e o universo têm os povos primitivos por nós conhecidos, (...) [que] atribuem a (...) espíritos e demônios a causação dos processos naturais, e consideram que não só os animais e plantas, como também as coisas inertes do universo, estão animadas por eles" (FREUD, 2014, p.79-80). Mais a frente ele acrescenta: mas "nós não estamos todavia bastante distanciados dela [da "filosofia da natureza" primitiva]" (FREUD, 2006, p.80). Segundo Freud, "o princípio que rege a magia, a técnica do pensar animista (para Freud, "o animismo é um sistema de pensamento") (FREUD, 2014, p.81) é a da 'onipotência dos pensamentos'” (FREUD, 2014, p.89), sendo que essa expressão - "onipotência dos pensamentos"- segundo o próprio Freud o diz, foi cunhada por um paciente que padecia de representações obsessivas, "o homem 
dos ratos" (FREUD, 2014, p.89), técnica essa que Freud constata também em outras neuroses: "em todas elas, o decisivo para a formação do sintoma não é a realidade objetiva do vivenciar, mas a do pensar" (FREUD, 2014, p.90). Sendo assim, podemos dizer que a onipotência dos pensamentos que caracteriza para Freud o pensamento primitivo não é visto por ele como uma fase superada pela civilização, não é visto por Freud como um passado longínquo em relação à civilização, pois ele o vê vivamente operando no pensamento dos seus próprios pacientes; o sistema de pensamentos do homem dos ratos é para Freud um exemplo do modo de operar do pensamento primitivo; a neurose, para Freud, opera tal qual os pensamentos ditos primitivo, e o homem dos ratos constitui para Freud um exemplo dessa estratégia do pensar. Talvez possamos também apontar nessa direção, e nisso a responsabilidade é nossa, e não de Freud, ao lembrarmos que a religião dos povos autodenominados civilizados também possui seu quinhão de animismo, embora proclamem ter expurgado esse tipo de pensar "pagão": no panteão dos rituais cristãos figura a presença de uma divindade animista - os anjos, seres antropomórficos, alados, misto de humano e ave, não possuem sexo, isto é, não são masculinos nem femininos, e são considerados seres enviados por Deus, estariam portanto mais próximos a Deus do que os seres humanos, já que estes teriam decaído pelo "pecado", pela força que neles exerceu as paixões carnais e a atração do "mal".

Por último, na quarta parte de Totem e tabu, Freud se ocupa com a questão do totemismo, assim definido por ele: "o totemismo é um sistema que entre certos povos primitivos da Austrália, América e África funciona às vezes como uma religião e proporciona a base da organização social” (FREUD, 2014, p.103). A introdução de classes matrilineares na organização dessas sociedades limitou a liberdade sexual e preveniu contra o incesto; mas, pergunta Freud: "De onde provém (...) o horror ao incesto, que deve discernir-se como sendo a raiz da exogamia? [E acrescenta:] (...) o incesto (...) não é um evento raro ainda em nossa sociedade de hoje" (FREUD, 2014, p.124). Com o que irá concordar Lévi-Strauss, para Freud a interdição do incesto não é exclusividade do povos ditos primitivos, pois é também estruturante nas famílias constituintes dos povos autodenominados civilizados. Eis, portanto, outra concordância entre a vida anímica dos neuróticos e a dos "primitivos": o horror ao incesto.

Para responder essa questão, Freud se apóia na "hipótese de Charles Darwin sobre o estado primordial do ser humano [a horda primordial]" (FREUD, 2014, p.127- 
128), inferida por Darwin não a partir da observação feita sobre uma comunidade humana (o que nunca foi visto), mas da observação de grupos de gorilas, aonde só se vê um macho adulto por cada grupo (FREUD, 2014, p.128). Para responder a essa pergunta Freud se apóia também na idéia do "banquete totêmico", termo criado pelo filólogo William Robertson Smith, físico e investigador da Antiguidade, da Bíblia, como suposição explicativa da origem da religião dos povos semitas (FREUD, 2014, p.135). É por conta dessa dimensão criacionista - pois que a "horda primitiva" e o "banquete totêmico" nunca foram vistos em lugar nenhum, constituindo antes, portanto, termos criados, suposições elaboradas com o fito de fornecer estruturas de inteligibilidade para o real das relações humanas - que Lacan dirá que tal obra de Freud, Totem e tabu, é ela própria um mito (LACAN, 1997, p.221), o que por sua vez parece muito incomodar aqueles que ainda hoje fazem uma interpretação colonial da psicanálise.

Com o mesmo estilo dos capítulos anteriores, Freud vai traçar uma aproximação entre as hipóteses de funcionamento da horda primordial de Darwin e do banquete totêmico ao modo de funcionamento característico da neurose vigente no seio da "civilização", ou melhor, talvez devêssemos dizer assim, no seio do malestar da civilização. Assim, ao canibalismo totêmico Freud compara a dieta da mulher em estado de gravidez, que evita "comer a carne de certos animais porque as suas indesejadas propriedades, a covardia por exemplo, poderiam ser transmitidas à criança que ela nutre" (FREUD, 2014, p.85) (esse também é um pensamento muito comum em meio aos adeptos do vegetarianismo). Com relação à identificação com o totem, Freud irá afirmar que a "conduta da criança em relação ao animal é muito parecida com a do primitivo. A criança não mostra nenhuma marca dessa arrogância que logo moverá o homem adulto da cultura a recusar com uma fronteira taxativa sua própria natureza frente à do animal" (FREUD, 2014, p.129), e como exemplo disso fará então referência ao caso observado por Ferenczi, o caso do pequeno Arpád, de dois anos, quando este disse: "Meu pai é o galo" (FREUD, 2014, p.133).

Por fim, em vista de concluir, gostaria de lembrar que Freud não é um autor civilizatório, nem tampouco de ordem moral e cívica; ao contrário de Augusto Comte e Marquês de Pombal, Freud não é um propalador do progresso da razão, da civilização e da humanidade; ao invés da "civilização", Freud é antes o autor do malestar na civilização. E relembrando seu texto de 1915, O inconsciente, a temporalidade de Freud não é a temporalidade do evolucionismo - malgrado Freud tenha sido influenciado pelo evolucionismo, dele reteve somente o que aí desferiu um 
golpe à presunção narcísica do homem, e não o que dele deu margem a uma apologia do progresso (das luzes, da consciência, da razão, e assim por diante) - nem é tampouco a temporalidade de Hegel, isto é, do progresso linear de uma consciência sensível e em permanente ascensão que por fim chegaria ao seu grau mais abstrato: a consciência absoluta. A temporalidade de Freud não é também a temporalidade do cristianismo, que parte do decaimento do homem e ruma na direção da sua salvação.

Ao contrário dessas posições, no texto $O$ inconsciente Freud dirá que uma das principais características do inconsciente não é a suposta temporalidade progressiva da civilização, nem tampouco do simbólico, mas justamente a sua atemporalidade (FREUD, 2006, p.37). O "tempo lógico" do qual falará Lacan não é o tempo do progresso da civilização, nem tampouco do simbólico, mas seu modo de expressar uma ruptura com a concepção cronológica e linear do tempo, como era o caso dos quarenta minutos de sessão preconizados pela IPA ("Institutional Psychoanalytical Association"), para que então o analista pudesse se fiar na lógica do inconsciente do próprio sujeito, isto é, o "tempo lógico" foi seu modo de fazer eco à atemporalidade da qual falava Freud. E para isso contribuiu não apenas o que Freud ouvia em sua clínica, mas também o fato de ter vivido no período em que se deflagraram as duas maiores guerras mundiais, onde os povos tidos até então como sendo os mais civilizados, os mais racionais, se viram protagonizando uma barbárie com proporções nunca antes vista. 


\section{REFERÊNCIAS}

FREUD, S. O inconsciente, in "Escritos sobre a Psicologia do Inconsciente", vol.2. Tradução de Luiz Alberto Hans. Rio de Janeiro: Imago Ed., 2006.

FREUD, S. Tótem y tabú: algunas concordancias en la vida anímica de los selvajes y de los neuróticos. Buenos Aires: Amorrortu, 2014.

LACAN, J. O mito individual do neurótico ou Poesia e verdade na neurose. Rio de Janeiro: Jorge Zahar, 2008.

LACAN, J. O Seminário, livro 1: os escritos técnicos de Freud. Rio de Janeiro: Jorge Zahar Ed.,1986.

LACAN, J. O seminário, livro 7: a ética da psicanálise. Rio de Janeiro: Jorge Zahar Ed., 1997.

LACAN, J. Nomes-do-Pai. Rio de Janeiro: Jorge Zahar, 2005. 


\section{TOTEM AND TABOO: DAILY LIFE}

\section{Abstract}

In this article the author tries to do a brief study above Totem und tabu: Einige Übereinstimmungen im Seelenleben der Wilden und der Neurotiker, a text written by Freud on 1913. Highlighting the key points discussed by Freud in each chapter, the main goal of the writer it's to show that in contrast to a kind of interpretation done, Freud did not write this text to distance "primitive" and "civilization", as if they were steps of maturation in a development process of the human being, linearly in evolutionary ascension. The temporality that guide Freud in Totem und Tabu don't try to distance "primitive" and "civilized", but to make them closer to each other, try to show what there are of concordance, as showed in the subtitle of the work: Einige Übereinstimmungen im Seelenleben der Wilden und der Neurotiker.

KEYWORDS: Psychoanalysis. Totem. Temporality. Indians. Civilization. 


\section{TOTEM ET TABOO: VIE QUOTIDIENNE}

\section{RÉSUMÉ}

Dans cet article l'auter essaye de faire un bref étude sur Totem und tabu: Einige Übereinstimmungen im Seelenleben der Wilden und der Neurotiker, texte écrit par Freud em 1913. En train de détacher les principaux points abordés par Freud dans chaque chapitre de l'oeuvre, le principal objectif de l'auteur est de présenter que contrairement à l'interprétation qui habituellement est faite par quelques-uns, Freud n'a pas écrit ce texte pour éloigner le "primitif" et la "civilisation", comme s'il s'agissait d'étapes de maturation du processus de développement de l'humain, linéairement en expansion evolutive. La temporalité qui guide Freud dans Totem und Tabu n'essaye pas d'éloigner "primitif" et "civilisé", mais les rapprocher l'un de l'autre, éssaye de présenter ce qu'il y a de concordance, comme montre le soutitre de l'oeuvre.

MOTS-CLÉS: Psychanalyse. Totem. Temporalité. Indiens. Civilisation. 
Recebido em: 02-03-2018

Aprovado em: 15-04-2018

(C) 2018 Psicanálise \& Barroco em revista

http://www.seer.unirio.br/index.php/psicanalise-barroco/index

revista@psicanaliseebarroco.pro.br

Programa de Pós-Graduação em Memória Social — UNIRIO.

Memória, Subjetividade e Criação.

http://www.memoriasocial.pro.br/proposta-area.php 